EPJ Web of Conferences 32, 04011 (2012)

DOI: $10.1051 /$ epjconf/20123204011

(C) Owned by the authors, published by EDP Sciences, 2012

\title{
3.6MW Power Supply System of the 170GHz ECH\&CD System in KSTAR
}

\author{
Eun-yong Shim ${ }^{1}$, Il-kun Ahn ${ }^{1}$, Tae-won Seo ${ }^{1}$, Seung-kyo Lee ${ }^{1}$ \\ Young-soon Bae ${ }^{2}$, Jin-Hyun Joung ${ }^{2}$, Mi Joung ${ }^{2}$ \\ ${ }^{1}$ Dawonsys company,Jeongwang-dong 1277-4, Siheung-si, Gyeonggi-do 429-850, Korea \\ ${ }^{2}$ National Fusion Research Institute, Gwahangno 113, Yuseong-gu, Daejeon 305-333, Korea
}

\begin{abstract}
A 3.6 MW (-66 kV/55 A) Gyrotron power supply system was developed for the $170 \mathrm{GHz}$ ECH\&CD gyrotron system in KSTAR. This power supply system consists of Cathode Power Supply(CPS), Anode Power Supply(APS) and Body Power Supply(BPS). The CPS is using the Pulse Step Modulation by the 32set of IGBT choppers. The respons time of Chopper is very fast. So the cathode voltaget is able to be controlled rapidly. The APS is a sort of voltage devider using zener and switch component. It was achieved $3 \mathrm{kHz}$ modulation operation. The BPS is combined the commercial power supply and special high voltage switches. It is very simple topology but $5 \mathrm{kHz}$ modulation was accomplished easily. Theses power supply system were installed and commissioned successfully in 2011. This paper presents the topology of the each power supply and test result for $170 \mathrm{GHz}$ gyrotron in KSTAR.
\end{abstract}

\section{Introduction}

The high voltage power supply system consists of a HVDC generator for supplying cathode voltage , an anode voltage controller (mod-anode), a body power supply (BPS). The HVDC generator is capable of supplying a maximum voltage of $-66 \mathrm{kV}$ and a current of $55 \mathrm{~A}$ to the cathode with respect to the collector and its DC voltage generation is based on the Pulse Step Modulation (PSM) principle which is a series connection of elementary rectifier and IGBT switching powermodules (called as chopper). The DC generation consists of 20 high voltage (HV) chopper stacks and 12 low voltage (LV) chopper stacks. The voltage regulation unit of individual chopper module of each HV chopper stacks and LV chopper stacks is $3 \mathrm{kV}$ and $0.5 \mathrm{kV}$, respectively. The highvoltage switching system for the cathode is made by parallel and series connections of many MOSFET fast solid-state switch of which switching time is less than 1 microsecond. It can turn on the high voltage pulse to the cathode with a rise time of 30 microseconds from $0 \mathrm{kV}$ to $60 \mathrm{kV}$ and the opening time of 4 microseconds. The anode voltage with respect to the cathode is controlled in a range of 0 to $60 \mathrm{kV}$ by using of voltage divider circuit for the beam current control between the cathode and the anode composing of a fixed resistor and many zener diodes which has function of variable resistor. Each zener diode has voltage holding of $200 \mathrm{~V}$, and it is shorted by closing the solid-state switch each parallel connected to each zener diode. The precise control of the anode voltage with respect to the cathode is required for the triode gun operation of the gyrotron which has advantage of pitch factor control of the electron beam without changing the beam voltage. The BPS supplies the positive voltage to the body with respect to the ground for the depressed collector of the gyrotron. The maximum voltage and current of BPS is $50 \mathrm{kV}$ and $150 \mathrm{~mA}$. The voltage output is regulated with stability of $1 \%$. For the higher frequency modulation, the parallel discharge switch is introduced between the cathode and anode in order to clamp the charged voltage in the stray capacitance between the cathode and anode. The series solid-state switch is also introduced in the BPS and on-off modulation up to $5 \mathrm{kHz}$ synchronized with mod-anode circuit is possible. This paper

This is an Open Access article distributed under the terms of the Creative Commons Attribution License 2.0, which permits unrestricted use, distribution, and reproduction in any medium, provided the original work is properly cited. 
presents the key features of DC generator, mod-anode, and body power supply for $170 \mathrm{GHz}$ gyrotron in KSTAR.

\section{Requirement of power supply}

The ECH/CD power supply needs following characteristics.

- Cathode to collector voltage $(\mathrm{Vkc})$ should be variable negative up to $60 \mathrm{kV}$.

- Cathode to collector voltage $(\mathrm{Vkc})$ should be no voltage drop even if beam current flow suddenly.

- Anode to cathode voltage $\left(\mathrm{V}_{\mathrm{AK}}\right)$ is variable positive.up to $60 \mathrm{kV}$.

- Anode to cathode voltage $\left(\mathrm{V}_{\mathrm{AK}}\right)$ should be able to modulate up to $5 \mathrm{kHz}$.

- Body to collector voltage $\left(\mathrm{V}_{\mathrm{BC}}\right)$ should be variable positive up to $50 \mathrm{kV}$.

- Body to collector voltage $\left(\mathrm{V}_{\mathrm{BC}}\right)$ should be able to modulate up to $5 \mathrm{kHz}$.

Fig1 shows the ideal voltage for the gyrotron but in practic, there are various defects such as ripple, drop, noise, instability, delay time, rising time, falling time etc. Table1 is the specification of the power supply system.

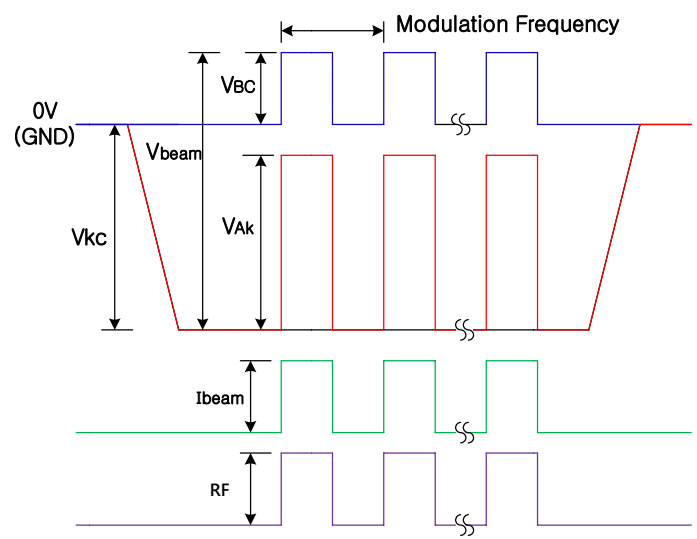

Fig 1. Ideal voltage source for Gyrotron

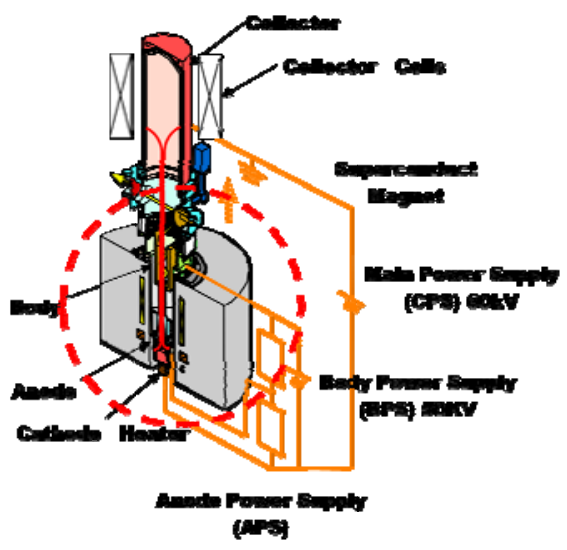

Fig 2. Connection of gyroton to power supply

Table1. the specification of the power supply

\begin{tabular}{|c|c|c|c|}
\hline $\begin{array}{c}\text { Electrical Operating } \\
\text { Parameters } \\
\end{array}$ & Minimum & Maxmum & Typical \\
\hline Cathode - Collector Voltage & -40 & -65 & $-60 k V$ \\
\hline Anode - Cathode Voltage & 30 & 50 & $40 \mathrm{kV}$ \\
\hline Body - Collector Voltage & 20 & 30 & $25 k V$ \\
\hline Beam Accel. Voltage & 60 & 90 & $85 \mathrm{kV}$ \\
\hline Beam Current & 15 & 55 & 45A \\
\hline Body Current & & $20 \mathrm{~mA}$ & $\sim 3 \mathbf{~ m A}$ \\
\hline Anode Current & & $20 \mathrm{~mA}$ & $\sim 3 \mathbf{~ m A}$ \\
\hline Power & 0.2 & 1.3 & $1 \mathrm{MW}$ \\
\hline Pulse Length & & $\mathbf{C W}$ & \\
\hline \multicolumn{4}{|l|}{ Regulation required } \\
\hline Beam Accel.Volatge & & $\pm 0.5 \%$ & \\
\hline Cathode - Collector Voltage & & $\pm 5 \%$ & \\
\hline Arc Energy to Gyrotorn & & $10 \mathrm{~J}$ & \\
\hline
\end{tabular}




\section{Single Line Diagram}

The single Line Diagram is shown in Fig 3. The Incoming is $22.9 \mathrm{kV}$. There is VCB for the $22.9 \mathrm{kV}$ and the transformer which makes the voltage down to $6.6 \mathrm{kV}$. the $6.6 \mathrm{kV}$ VCB is installed after the transformer. The VCS with pre-charging VCS and pre-charging resistor in parallel for the HV chopper and the LV chopper is used. After VCS, there are 4set of HV chopper transformers and 1 set of LV chopper transformer that supply the proper voltage for the choppers. The HVDC generator consists of 20 high voltage (HV) choppers and 12 low voltage (LV) choppers. The HVS is installed at the end stage of output for the openning the gyrotron from the HV circuit at the arcing. This output is connected to the cathode of gyrotron.

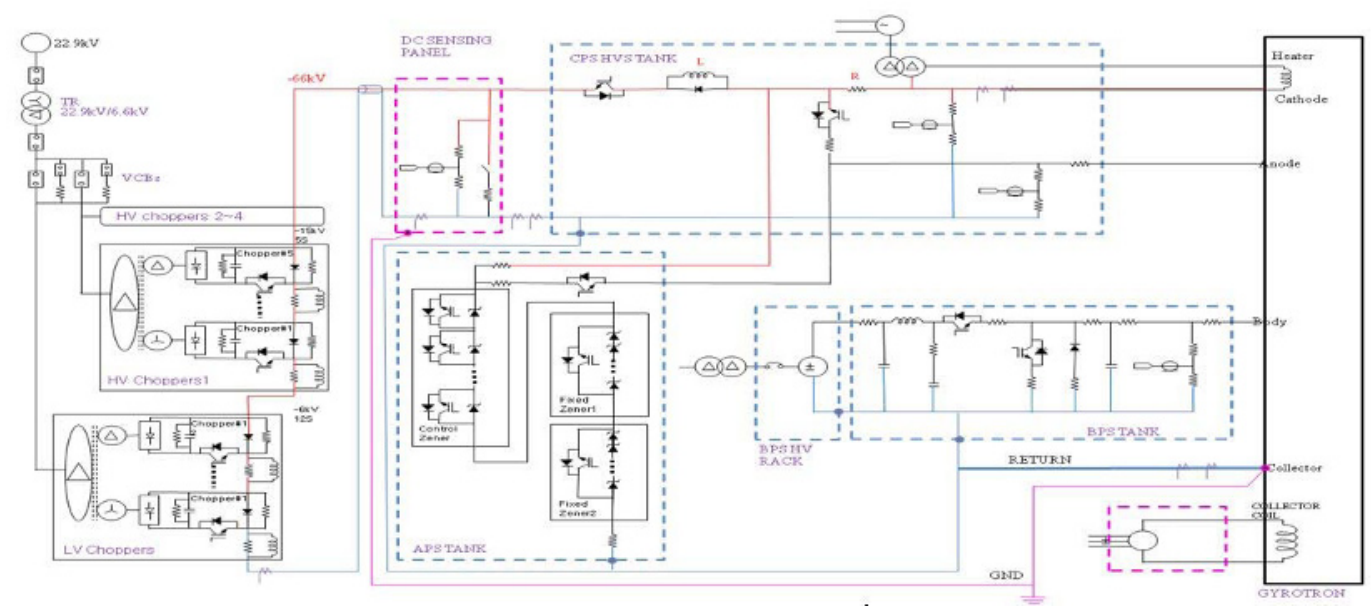

Fig 3. Single Line Diagram

The APS is the a sort of voltage divider using zeners and resistors. The APS controls the voltage between the catode and anode of gyrotron in a range of 0 to $60 \mathrm{kV}$. The discharging switch is equiped for high frequency modulation up to $5 \mathrm{kHz}$.

The BPS consist of high voltage source and high voltage switches. It is connect to the body and collector.and supply the positive voltage. The resistor, Rs is connected at output stage. The function of Rs is the surge suppression at the arc situation.

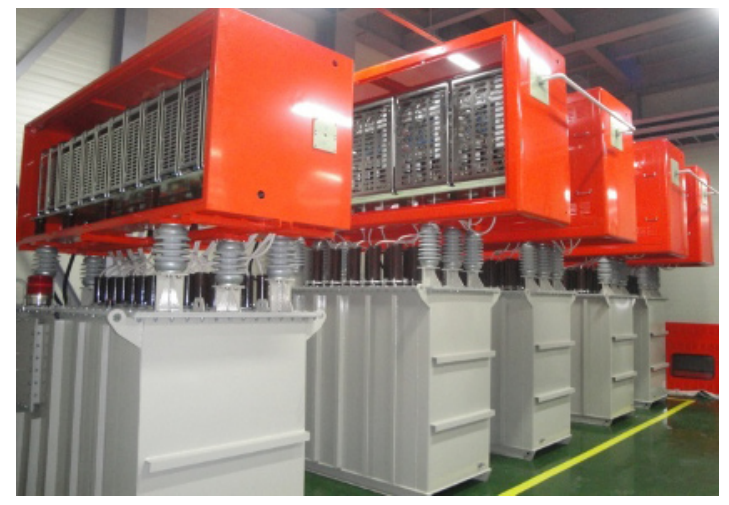

Fig 4. CPS Choppers

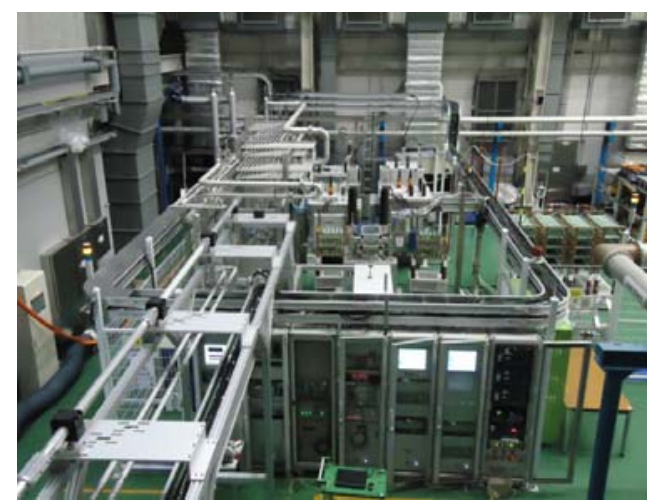

Fig 5. APS, BPS, HVS, Control system 


\section{Power Supply Topology}

This power supply system is composed of three power supplies. Cathode power supply(CPS), anode power supply(APS) and body power supply(BPS).

\subsection{CPS}

The CPS is full chopper type power supply. It consist of 20set HV choppers and 12set LV choppers. All chopper is connected in series each other. The chopper uses the two kinds of IGBTs. The $6500 \mathrm{~V} / 400 \mathrm{~A}$ IGBT is for HV chopper. The $1200 \mathrm{~V} / 400 \mathrm{~A}$ IGBT is for LV chopper. The output of $\mathrm{HV}$ chopper and LV chopper is $3 \mathrm{kV}$ and $0.5 \mathrm{kV}$. The total output voltage is $66 \mathrm{kV}$. Full chopper type HVDC generator has a following advantages.

- fast compensation of the voltage drop

- fast rising time without HV switch

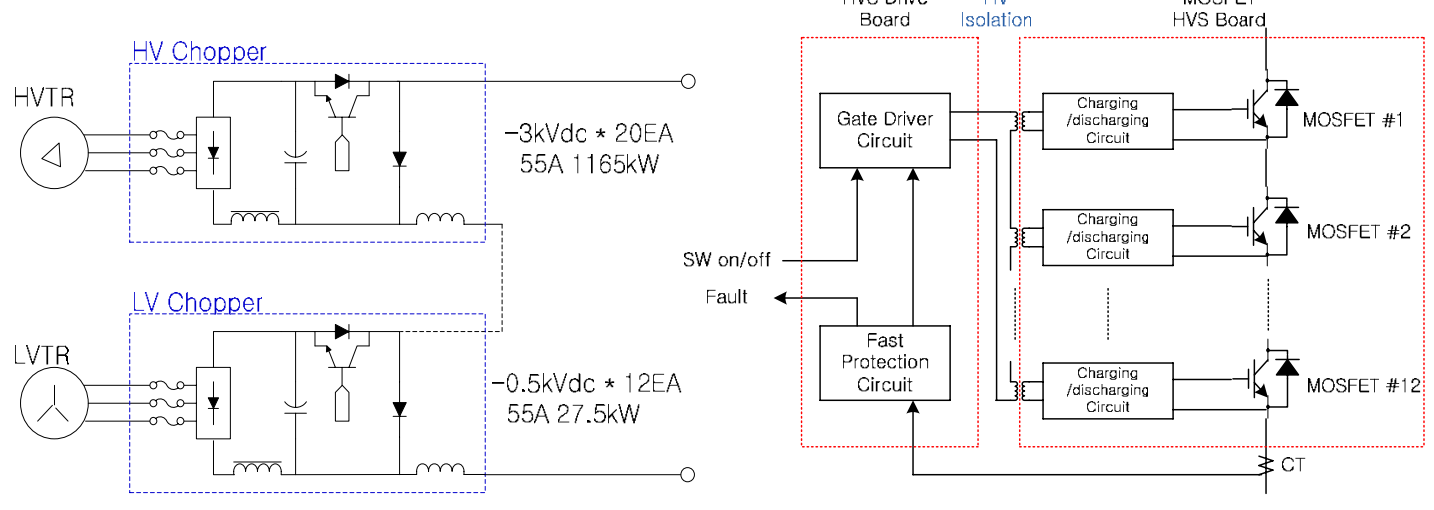

Fig 6. Chopper circuit

Fig 7. Main configuration of HVS

\subsection{HVS system}

The CPS has the high-voltage switching system at the final output stage. The HV switching system for the cathode is made by parallel and series connections of many MOSFET fast solid-state switch of which switching time is less than 1 microsecond. It can turn on the high voltage pulse to the cathode with a rise time of 30 microseconds from $0 \mathrm{kV}$ to $60 \mathrm{kV}$ and the opening time of 4 microseconds. The main function of HVS is the openning the CPS from the cathode of gyrotron at the arcing. The HVS system has the reactor for limitation of current rising rate during the arcing time. But this reactor cause the voltage drop of CPS at the moment of beam current starting. So proper value of reactance has to be seleted to minimise the voltage drop. The freewheeling diode is connected to the reactor in parallel. The resistance of freewheeling loop has to be minimised for less voltage drop.

\subsection{APS}

APS is using the zener and the resistor to divide the voltage There are 2ea large voltage zener of $20 \mathrm{kV}$ and $96 \mathrm{ea}$ small voltage zener of $200 \mathrm{~V}$. The all zener have the switch in parallel to bypass the zener. The voltage of the each zener become zero when the switch is on. Therefore APS voltage is adjusted by the number of switch on. Fig 8 . shows the APS circuit diagram. APS has the function of modulation that frequency is up to $5 \mathrm{kHz}$. Modulation is charging and discharging of the parasitic 
capacitance between cathode and anode. The discharging switch is installed for fast discharging. Fig 9. show the test of APS.

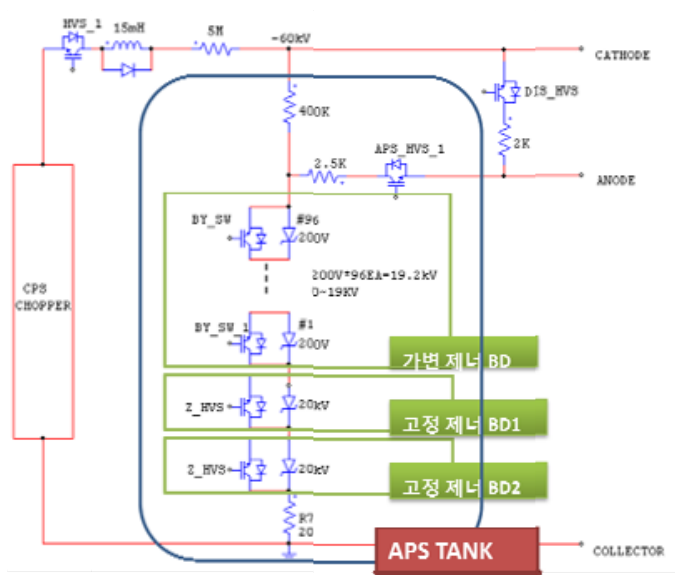

Fig 8. APS circuit diagram

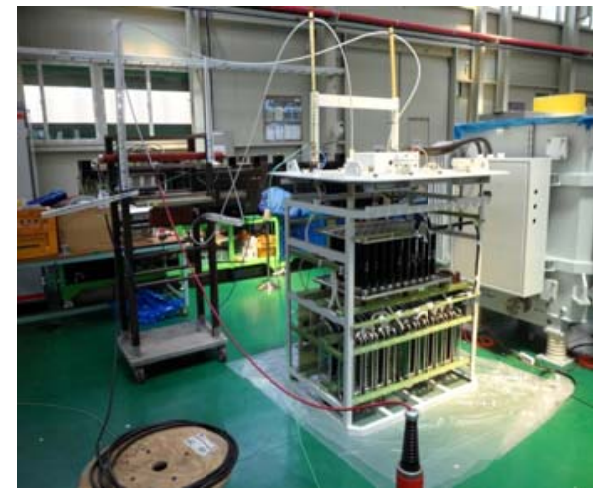

Fig 9. APS test

\subsection{BPS}

The topology of BPS is to combine the HVDC generator and the HV switch technology. The Body to collector voltage of gyrotron needs about $+25 \mathrm{kVdc}$ or modulated pulse. The HVDC generator is commercial HVDC Power supply. There is two kinds of HV switch in the BPS for charging and discharging. We also use the discharging switch for high frequency modulation up to $5 \mathrm{kHz}$.

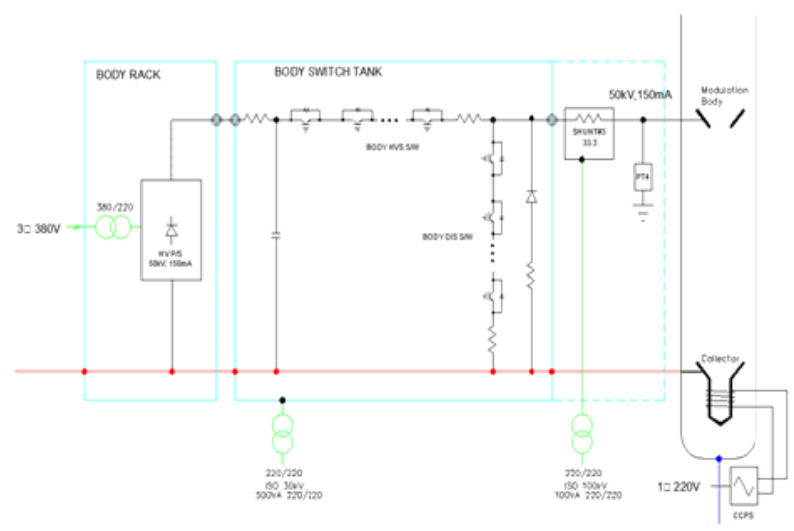

Fig 10. BPS circuit diagram

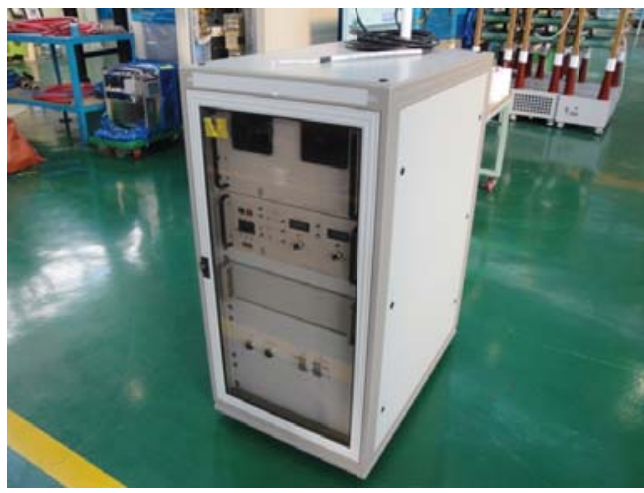

Fig 11. BPS HVDC Generator

\section{Experimental Result}

This power supply system was manufactured and done the factory test and installed at the NFRI. The commissioning test was implemented and used at the KATAR campaign. The test result was achieved as belows.

\subsection{CPS}

Fig 12. is waveform of output of CPS while HV opening switch is on. HV switch is normally on before chopper running. It takes less than $2 \mathrm{~ms}$ from $0 \mathrm{~V}$ to $66 \mathrm{kV}$. 


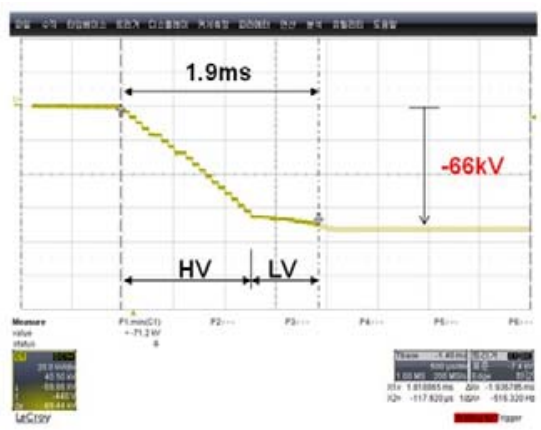

$\mathrm{CH} 1: \mathrm{V}_{\mathrm{KC}}$ voltage between cathode and collector $(20 \mathrm{kV} / \mathrm{div})$

Fig 12. Output voltage waveform of CPS

\subsection{HVS Arcing test}

$-60 \mathrm{kV}$ is applied between the arc gap switch

- dissipation energy at the test wire was less than 0.25 Joule

-Dissipation energy calculated by equation of $E=\int V \times I d t$

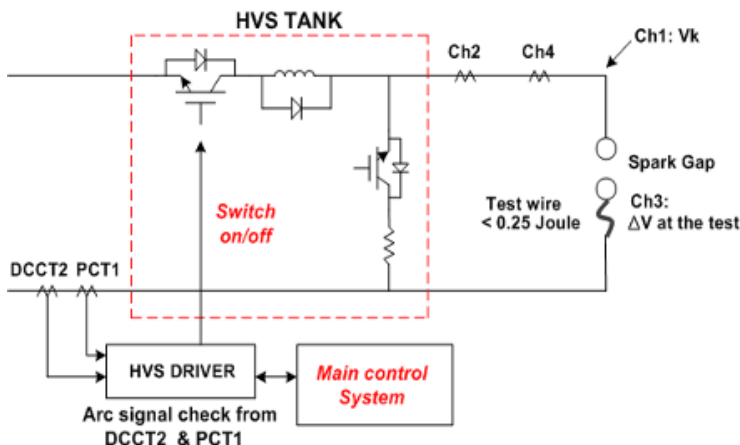

Fig 13. Arc test circuit diagram

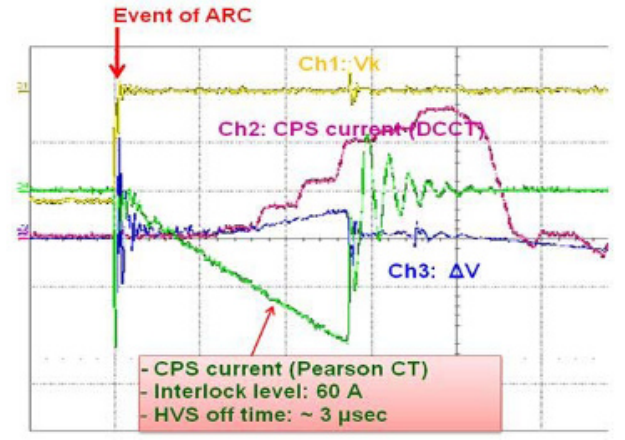

Fig 14. waveform of Arc test

\subsection{APS}

There are two important things for the APS. First one is minimising the parasitic capacitance. Second one is

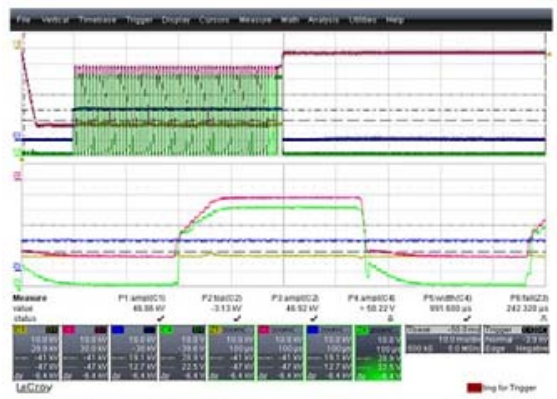

$\mathrm{CH1}: \mathrm{V}_{\mathrm{KC}}$ voltage between cathode and collector (10kV/div) $\mathrm{CH} 2: \mathrm{V}_{\mathrm{AC}}$ voltage between anode and collector (10kV/div) $\mathrm{CH} 3: \mathrm{V}_{\mathrm{BC}}$ Bady voltage (10kV/div)

$\mathrm{CH} 4:$ I IEAM cathode current (10A/div)

Fig 15. Output voltage waveform of APS

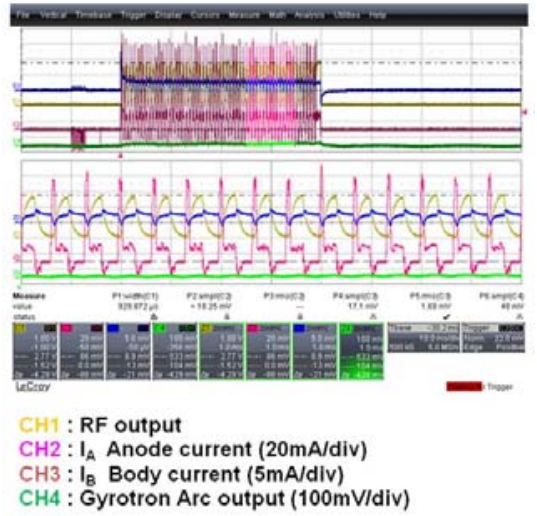

Fig 16. RF Output waveform 
maximising the charging current considering the power loss. Modulation frequency is limited by above two factor. Fig

15 shows the waveform of APS at $3 \mathrm{kHz}$ modulation while gyrotron is operating. Rising time of $\mathrm{V}_{\mathrm{AC}}$ is about 80us due to the parasitic capacitance.

\subsection{BPS}

Fig17, Fig 18 show the test circuit and waveform.

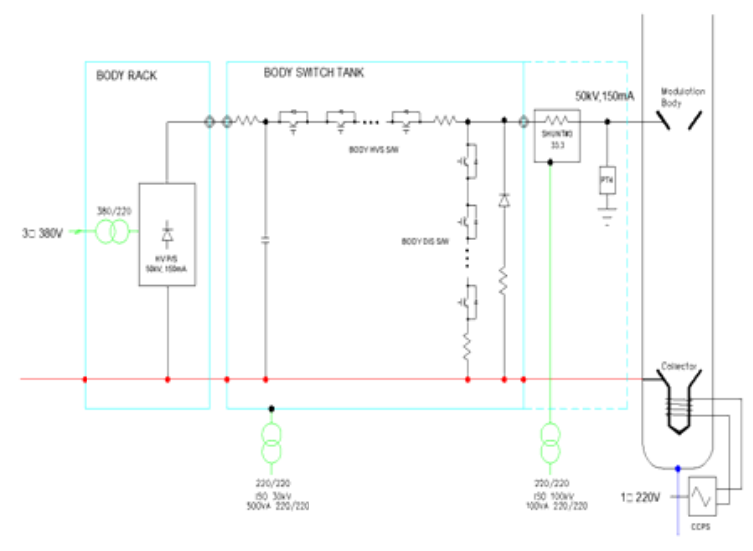

Fig 17. Test circuit of BPS
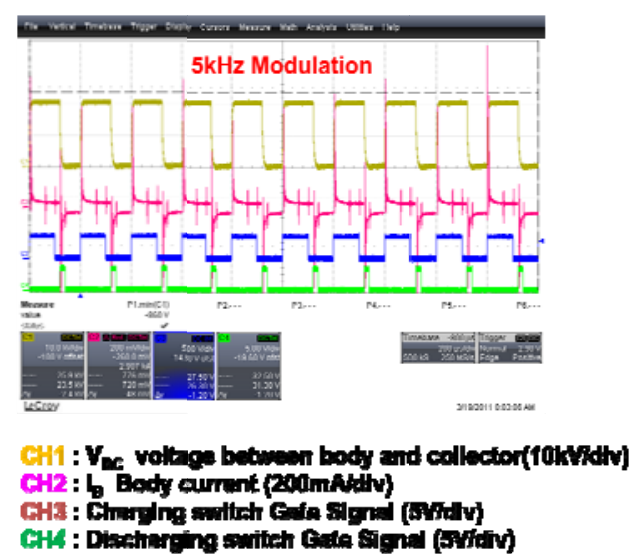

Fig 18. Output voltage waveform of BPS

\section{Conclusion}

The full chopper type has a large number of outstanding features :

- Minimization of switching losses owing to the less number of switching.

- Fast compensation time of voltage drop and regulation.

- Fast rising time with HV fast switch.

The additional study and test as followings will be done :

- To minimize the CPS voltage drop by chopper control (feedback \& feedforward control)

- To increase the APS Modulation frequency more than $5 \mathrm{kHz}$.

- Long pulse operation up to 300 sec with $1 \mathrm{MW}$ RF output

To conclusion, the full chopper type power supply system was found to be suitable for gyrotron application. 